\title{
SAÚDE DA POPULAÇÃO LGBT PARA ALÉM DO HIV/AIDS E PROCESSO TRANSEXUALIZADOR NO SUS
}

\author{
Felipe Cazeiro da Silva ${ }^{1}$
}

\begin{abstract}
Resumo: O presente artigo é um recorte de duas pesquisas empíricas realizada no âmbito da saúde LGBT, especificamente no Processo Transexualizador e na assistência em HIV/Aids. Assim, o artigo intenta levantar reflexões acerca do conjunto de racionalidades que perpassam os processos de configuração da saúde LGBT, discursos e políticas envolvidas através do relato de 11 participantes. Tratase de uma pesquisa qualitativa que reuniu relatos de 6 mulheres trans, 3 homens trans e 2 homens cis gays. Os dados foram coletados por entrevistas semiestruturadas e analisados mediante Análise de Conteúdo. Os resultados mostram importantes pontos críticos no campo da saúde, especialmente da saúde de pessoas trans sendo a peregrinação pelos serviços de saúde demarcada por constantes discriminações institucionais permitindo o entendimento de como o sistema de saúde se organiza em relação ao atendimento destas pessoas elencando questões para o trabalho de profissionais da saúde e agentes governamentais neste campo.
\end{abstract}

Palavras-chave: Saúde da população LGBT. HIV/aids. Processo Transexualizador.

\section{INTRODUÇÃO}

O presente artigo objetiva levantar reflexões a partir de duas pesquisas que foram realizadas pelo autor no âmbito da saúde de pessoas LGBT: Uma sobre o Processo Transexualizador e outra sobre HIV/aids. A primeira pesquisa, nível de graduação (TCC), foi realizada em 2016 objetivando compreender os relatos de pessoas trans residentes na cidade de Cuiabá-MT em sua busca pelo Processo Transexualizador (PT) no Sistema Único de Saúde (SUS). A segunda pesquisa, nível de mestrado (Dissertação), foi realizada no período de 2018 objetivando compreender os relatos de mulheres trans e homens cis gays residentes na cidade de Natal (RN) sobre os sentidos e desafios de viver com HIV.

1 Doutorando e Mestre em Psicologia pelo PPGPSI da Universidade Federal do Rio Grande do Norte (UFRN).

Vol. 03, N. 11, Jul. - Set., 2020 - http://periodicoscientificos.ufmt.br/ojs/index.php/rebeh/index 
Assim, este trabalho parte de uma mirada política e social permitindo integrar demandas e questões que a população LGBT coloca para o campo da saúde e sociedade, bem como para compreender como esta população opera nas malhas do SUS e suas manobras para garantia de demandas específicas visto que o modo de viver, delineado pelo contexto em que cada pessoa está inserida, produz vivências e cuidados diferenciados e que são relevantes para uma compreensão mais integral em saúde, principalmente quando se propõe superar a lógica de saúde voltada para a população LGBT restringida ao HIV ou ao Processo Transexualizador (Laurentino, 2015).

A visibilidade das questões de saúde de LGBT deu-se a partir dos anos 80, quando o Ministério da Saúde adotou estratégias para o enfrentamento da epidemia do HIV/aids, sobretudo pela pressão dos movimentos sociais LGBT. Como um movimento incipiente ele era majoritariamente composto por pessoas cisgênero e homossexuais que excluíam a participação de pessoas trans e travestis que foram atrizes centrais e pioneiras para a luta e organização da comunidade LGBT (FACHINNI, 2009).

O posterior reconhecimento da complexidade da comunidade LGBT exigiu que se ampliasse o conjunto de suas demandas em saúde através da especificidade de cada grupo promovendo uma política de caráter transversal, de combate as discriminações, desigualdades e inequidades em saúde, bem como relacionadas à produção de conhecimento, participação social, promoção da saúde, cidadania, atenção e cuidado visto que a porta de entrada para a saúde LGBT estava sendo realizada quase que exclusivamente pelos serviços de HIV/aids.

Desta forma, destaca-se a relevância deste estudo em função de ser um tema amplamente discutido e destacado no âmbito das questões sociais e das ações de saúde, bem como por abordar o que as pessoas LGBT têm a dizer sobre a área da saúde. Sua importância se amplia ao considerarmos a demanda crescente por profissionais com formação adequada para assistir a população LGBT, aliada à carência de profissionais com tal capacitação desvelando-se na ponta dos serviços em discriminações institucionais.

Albuquerque et al. (2013) expõe que a população LGBT possuem suas necessidades de saúde negadas plenamente por estar submetida à discriminação além de ter que lidar com o temor de que revelar sua orientação sexual e identidade de gênero 
nos serviços de saúde possa trazer uma repercussão negativa ao atendimento ou até mesmo se desvelar em uma agressão física.

Portanto, é urgente a concretização dos princípios constitutivos do SUS de universalidade, integralidade e equidade, expressos em políticas públicas que de fato promovam o enfrentamento da LGBTfobia e da cis-heteronormatividade na saúde, assim como dos eixos da Política Nacional de Saúde Integral LGBT (PNSI-LGBT).

Desta forma, se faz necessário reafirmar um conceito mais ampliado de saúde que atue em conjunto com a perspectiva dos direitos humanos e de cidadania (Figueiredo et al., 2009). Adota-se nesta publicação o que a Organização Mundial da Saúde (OMS) elaborou em 1947, que define a saúde como "um estado de completo bem-estar físico, mental e social e não apenas a ausência de doença ou enfermidade" (OPAS, 2018, p. 4).

Além disso, inspira-se em Paulo Freire (2001; 2005) e Georges Canguilhem (2002) os quais retratam o processo de autonomia das pessoas/coletividade para o alcance e manutenção da saúde e a constituição de uma "normalidade" social, vista sob a perspectiva de atenção aos direitos e deveres dos cidadãos, numa relação de corresponsabilidade entre o Estado e a Sociedade.

\section{NOTAS SOBRE O CAMPO DA SAÚDE DA POPULAÇÃO LGBT}

Inicialmente é preciso compreender que a saúde, de forma universal, sem distinção de raça, cor, orientação sexual ou identidade de gênero, passou a ser um direito garantido a partir da Constituição Federal de 1988 em decorrência de lutas como a do Movimento da Reforma Sanitária (Paiva \& TEIXEIRA, 2014). Todavia, mesmo diante dessa importante conquista, o acesso aos serviços de saúde ainda tem se caracterizado como excludente e discriminatório para alguns grupos minoritários, como a população LGBT, população negra, indígena entre outras (Paula, Silva \& Bittar, 2017).

De acordo com o retrato histórico da saúde da população LGBT, percebe-se a importância das determinações sociais em saúde geradas segundo a orientação sexual e a identidade de gênero no processo saúde-doença-cuidado. A população LGBT é um grupo que foi especialmente vulnerabilizado com o surgimento da aids nos 80 sendo Vol. 03, N. 11, Jul. - Set., 2020 - http://periodicoscientificos.ufmt.br/ojs/index.php/rebeh/index 
retratada como um "grupo de risco" para a "câncer gay". Tal conotação irracional funcionou para estigmatizar e discriminar ainda mais essa população promovendo diversos tipos de violência. (CAZEIRO, 2019)

Assim, este é um grupo que segue marginalizado e oprimido na sociedade, como, por exemplo, na Segunda Guerra Mundial, quando, nos EUA, pessoas com orientação sexual diferente da heterossexual eram submetidas a diversos tratamentos de reversão da sexualidade que era compreendida como uma patologia, um desvio, antinatural e anormal. (Louro, 2006). Em decorrência disso e de outas violências, houve a morte de muitos LGBT nesse período que se perpetua até os dias atuais sendo o Brasil um dos países que mais mata pessoas LGBT, principalmente pessoas trans segundo dados da ONG Transgender Europe (TGEu). (TEGEU, 2017)

Kahhale (2010) nos lembra que o processo de normalização em nossa sociedade foi reflexo do que interessou aos seres humanos valorizar, mas que não é natural, não está dado e nem é eterno. Sendo assim, os moldes de saúde e normalidade necessitam de uma consideração histórica para entender a saúde como uma busca constante de equilíbrio do sujeito com o todo, em um tempo e espaço, produzida socialmente. (KAHHALE, 2010).

Apresenta-se esta perspectiva de saúde-doença no intuito de superar a dicotomia indivíduo e sociedade e romper com a visão de saúde estritamente individual tomando-a como um sistema processual complexo produzido concomitantemente no plano individual e social (Kahhale, 2010).

Neste sentido, o percurso de despatologização da homossexualidade e da transexualidade revela esse paradigma no campo individual e social. A despatologização da homossexualidade ocorreu na década de 90 com a revisão, em 1987, do Manual Diagnóstico e Estatístico dos Transtornos Mentais (DSM) da Associação Psiquiátrica Americana (APA), retirando a homossexualidade do rol de doenças - Código Internacional de Doenças (CID) - em 1993. (Russo \& Venancio, 2006; OMS, 1993)

Contudo, a Transexualidade ainda continua sendo apresentada no referido manual como Condições Relativas à Saúde Sexual. Ainda que não seja mais categorizada como um Transtorno Mental a realocação ainda evidencia a manutenção 
da psicopatologização das experiências trans mesmo que as alterações tenham sido uma grande conquista em termos de movimento social visto que não se excluiu completamente a transexualidade do referido manual tal qual se deu com a homossexualidade (CAZEIRO, SOUZA \& BEZERRA, 2019).

No Brasil, o Conselho Federal de Psicologia, na resolução ${ }^{\circ}$ 001, de 22 de março de 1999, passou a proibir os psicólogos de realizarem atendimentos às pessoas LGBT com a finalidade de reverter à orientação sexual, além de promoverem a Nota técnica sobre o processo transexualizador e demais formas de assistência às pessoas trans (2013) para uma atuação psi menos patologizadora ainda que o processo para cirurgia esteja condicionado a um laudo patológico após a compulsoriedade de psicoterapia por 2 anos solicitados pelo Conselho Federal de Psicologia (CFM). (CFP, 2013; Laurentino, 2015; Pacheco, 2017)

No âmbito das políticas públicas, um importante marco foi à criação do programa Brasil sem Homofobia - Programa de Combate à Violência e à Discriminação contra LGBT e de Promoção da Cidadania Homossexual, em 2004. Foi instituído pelo Conselho Nacional de Combate à Discriminação e teve ampla participação social da sociedade. Compreende-se que este programa foi um dispositivo disparador da busca pela integralidade e universalidade da saúde dessa população historicamente oprimida e que, por este motivo, estabeleceu diretrizes para o combate à violência, preconceito e à discriminação, além do reconhecimento às especificidades e de promoção da cidadania (Brasil, 2004).

Uma ação importante que vale destacar foi a possibilidade do Programa Brasil sem Homofobia em articular a criação de Centros de Referência em Direitos Humanos LGBT (CR-LGBT) em 2007 através de um financiamento público via edital lançado em 2005 pela Secretaria Especial de Direitos Humanos da Presidência da República (SEDH/PR). Como expõem Lopes e Aragusuku (2018), muitos se transformaram em Centros de Referência em Direitos Humanos de populações vulneráveis, atendendo um público muito mais amplo e invisibilizando uma política pública de visibilidade e enfoque no combate à violência e discriminação contra pessoas LGBT

Vale lembrar também que muito antes do lançamento do Programa Brasil sem Homofobia, as primeiras ações do governo federal direcionadas à população LGBT 
foram construídas no âmbito do enfrentamento ao HIV/aids nos anos 80. Em decorrência do pânico social gerado, a partir do crescimento do número de infecções pelo HIV e dos casos de aids ambos desconhecidos cientificamente, o governo federal passou a realizar ações que buscavam atenuar os impactos da epidemia que inicialmente afetou de maneira mais direta grupos sociais específicos elencando estigmas para que se falasse em uma 'doença dos $5 \mathrm{H}$ ' de Homossexuais, Hemofílicos, Haitianos, Heroinômanos (usuários de heroína injetável) e Hookers (denominação em inglês para as profissionais do sexo) (Brasil, 1982).

Assim, a porta de entrada para a saúde LGBT começou a ser instituída pelos serviços de HIV/aids já que esta população estava sendo responsabilizada pela sociedade (Câncer Gay2) e ciência (GRID3) pelo advento da aids.

Uma das facetas de discriminação proveniente desse contexto foi a restrição da doação de sangue por pessoas LGBT configurados na consideração de inaptos temporários por 12 (dozes) meses no Art. 64 previsto na Portaria $n^{\circ} 158$, de 4 de Fevereiro de 2016, especificamente no inciso "IV - homens que tiveram relações sexuais com outros homens e/ou as parceiras sexuais destes" (Brasil, 2016, p. 10), que ganhou grande repercussão em 2020 por ter sido vetada pelo Supremo Tribunal Federal (STF) transformando-se em uma grande conquista pelos movimentos sociais. Este item excluía homens homossexuais com vida sexual ativa, mesmo que estivessem com parceiro único e fixo, além de homens bissexuais, pessoas trans e homens que fazem sexo com outros homens (HSH) demonstrando-se assim o caráter da discriminação e seletividade.

Certamente, a política de HIV/aids é um exemplo de iniciativa bem-sucedida no sentido de assegurar universalidade, integralidade e equidade no acesso à saúde no SUS sendo um modelo referenciado mundialmente (Fonseca, 2005). Contudo, esta não deve ser a única porta de acesso da população LGBT aos serviços de saúde. A população

2 "No início, e até julho de 1983, todos os termos empregados fazem referência ao grupo mais frequentemente associado à doença, os homossexuais: "pneumonia dos homossexuais", "câncer dos homossexuais" ou "câncer gay" e, mais amplamente, "síndrome dos homossexuais" ou "síndrome gay"” (HERZLICH \& PIERRET, 2005, p. 78).

${ }^{3}$ As infecções por HIV também foram validadas pelos meios científicos, especialmente pelo Centers for Disease Control and Prevention (CDC - EUA), como Gay Related Immune Deficiency (GRID) pela incidência majoritariamente em homens homossexuais considerando-os, equivocadamente, como vetores da doença, portadores de distúrbios, anomalias e perversões (DANIEL \& PARKER, 1991; BASTOS, 2006).

Vol. 03, N. 11, Jul. - Set., 2020 - http://periodicoscientificos.ufmt.br/ojs/index.php/rebeh/index 
LGBT é uma população que possui diversas demandas como qualquer outro grupo.

Percebe-se, assim, um desafio em assegurar que as práticas já desenvolvidas no âmbito do HIV/aids sejam expandidas para todas as ações do SUS, de maneira a garantir que pessoas LGBT encontrem atendimento de qualidade, humanizado e sem discriminação quando buscarem cuidados para sua saúde.

Portanto, foi no período de 2004, durante o primeiro governo do Presidente Lula (2003-2006), marcando também a criação do Comitê Técnico LGBT no Ministério da Saúde que esse campo começa a passar por transformações.

\begin{abstract}
Ainda que o movimento LGBT tenha críticas consistentes à atuação do Ministério da Saúde, e em particular ao Departamento de DST, Aids e Hepatites Virais, no tocante as ações de prevenção ao HIV específicas para LGBT (como a diminuição do repasse de recursos para ONGs e a escassez de campanhas de prevenção, nos meios de comunicação de massa) deve ser registrado que é na área da saúde que a população LGBT começa a ser alvo de políticas públicas efetivas, ou seja, formuladas e executadas a partir de diretrizes de alcance nacional, com previsão orçamentária específica, com atribuições e competências definidas e com impactos concretos sobre a vida das pessoas a partir de uma perspectiva integral e não mais apenas focada no combate às DST/Aids (MELLO; BRITO \& MAROJA, 2012, p. 422).
\end{abstract}

Em 2008, por força dos movimentos sociais, o Processo Transexualizador no

SUS foi conquistado e segundo o Portal de Saúde do Governo Federal (2016) está instituído pelas Portarias $\mathrm{n}^{\circ} 1.707$ e $\mathrm{n}^{\mathrm{o}} 457$ de agosto de 2008 sendo ampliado pela Portaria $\mathrm{n}^{\mathrm{o}} 2.803$, de 19 de novembro de 2013 garantindo o atendimento integral de saúde às pessoas trans, incluindo acolhimento e acesso com respeito aos serviços do SUS, desde o uso do nome social, passando pelo acesso a hormonioterapia até os procedimentos cirúrgicos (Brasil, 2016).

Ainda que com grande entraves e por não estar habilitado em todos os estados e municípios do Brasil, o Processo Transexualizador tem se tornado um potencial serviço para o cuidado de pessoas trans e suas demandas específicas para a transição de gênero demonstrando a necessidade de melhor investimento, ampliação e fortalecimento.

Posteriormente, em 2011, o Ministério da Saúde (MS) instituiu por meio da Portaria $\mathrm{n}^{\circ} 2.836$, de $1^{\circ}$ de dezembro de 2011 a Política Nacional de Saúde Integral de LGBT (PNSI-LGBT) que tem como objetivo a promoção da saúde integral de LGBT através da eliminação da discriminação e preconceito institucional, redução das 
desigualdades e consolidação do SUS como sistema universal, integra e equitativo objetivo (Brasil, 2013)

Vale salientar que as políticas de saúde voltadas para a população LGBT foram, majoritariamente, construídas e "estimuladas" pelos próprios movimentos sociais LGBT. Esse movimento de disputa e pressão permitiu o empoderamento a tal questão visto que mesmo com todos os avanços na área da saúde, a discriminação institucional e a invisibilidade entre os profissionais ocultaram ainda mais essa população, fazendo desses espaços destinados a promover saúde como lugares incapazes de atender e assistir às reais necessidades dessa população (Laurentino, 2015; Mello et al., 2011).

Laurentino (2015, p. 42) faz um "resgate histórico da política de saúde para a comunidade LGBT" em sua dissertação de mestrado que compreende o início dessa atenção para com as pessoas LGBT no contexto da aids com a criação do Programa Nacional de DST/aids em 1986. Demonstra que o período de 2002 a 2013 foi o período com maior destaque e força na agenda pública de saúde e cidadania para população LGBT, tendo especial fortalecimento dos direitos LGBT em 2011.

Assim como toda política voltada para minorias sociais, as políticas voltadas à população LGBT constantemente são ameaçadas de serem extintas ou atacadas a depender dos representantes que estão em cargos públicos (Laurentino, 2015), principalmente quando estes estão aliados ao conservadorismo e fundamentalismo religioso como o governo de Jair Messias Bolsonaro (2019-2022) que não mede esforços para promover diversos retrocessos na agenda LGBT (Galindo et al, 2017; CAZEIRO, NOGUEIRA DA SILVA \& SOUZA, 2020)

Desta forma, cumpre continuar reafirmando uma política de saúde LGBT como integrante da cobertura do SUS como a Política Nacional de Saúde Integral LGBT (PNSI-LGBT) para o fortalecimento do desenvolvimento de planos de ação abrangentes de saúde LGBT em níveis municipais, estaduais e federais, com forte participação social da comunidade LGBT visto que como reconheceu a OMS: O estigma e a discriminação são as principais barreiras de acesso a saúde para a população LGBT (OMS/OPAS, 2016). 
O presente trabalho é um recorte de duas pesquisas realizadas no âmbito da saúde de pessoas LGBT, especificamente sobre o Processo Transexualizador no SUS e sobre a assistência em HIV/aids.

No que tange a primeira pesquisa4, foram realizadas entrevistas semiestruturadas com 3 (três) mulheres trans e 3 (três) homens trans em torno da Universidade Federal de Mato Grosso (UFMT) e na Coordenadoria de Regulação de Cuiabá-MT no período de maio a agosto de 2016. A pesquisa foi aprovada sob o número do parecer: 1.487.878 e CAAE: 53595615.7.0000.5690 pelo Comitê de Ética em Pesquisa. As interlocutoras e interlocutores assinaram o Termo de Consentimento Livre e Esclarecido, sendo respeitado a decisão voluntária de participar ou não da pesquisa, bem como foi garantido o anonimato trocando os nomes.

No que diz respeito a segunda pesquisa5, foram realizadas entrevistas semiestruturadas com 2 homens cis gays e 3 mulheres trans héteros em torno da Associação Vidas Positivas de Natal-RN, Fórum LGBT Potiguar e da Articulação Aids do Rio Grande do Norte que são entidades que congregam atuações nas áreas de prevenção, assistência e controle social em HIV/aids no período de Março à Junho de 2018. A pesquisa foi aprovada sob o número do parecer: 2.456.454 e CAAE 80926017.7.0000.5537 pelo Comitê de Ética em Pesquisa. As interlocutoras e interlocutores assinaram o Termo de Consentimento Livre e Esclarecido destacando nele a concordância pela revelação de seus nomes. Tal consenso reflete à atuação destas pessoas dentro da militância, ao longo de suas vidas, que potencializa a percepção de que não era necessário esconder seu diagnóstico e sua identidade para a contribuição com a pesquisa.

O corpus desse trabalho foi baseado nos relatos das pessoas entrevistadas. Para a leitura dos dados, utilizou-se a análise temática de conteúdo (Bardin, 2011). Este tipo de método prevê três fases basilares: 1) A pré-análise; 2) A exploração do material e 3) O tratamento dos resultados, inferência e interpretação (Bardin, 2011). Na pré-análise o material passou por uma leitura flutuante com objetivo de torná-lo operacional

\footnotetext{
${ }^{4}$ Pesquisa de TCC em Psicologia. O artigo com os resultados dessa pesquisa foi aceito para publicação na revista Psicologia em Estudo com previsão de publicação para 2022: (CAZEIRO et al, No prelo)

${ }^{5}$ Pesquisa de Dissertação de Mestrado em Psicologia (CAZEIRO, (2019).

Vol. 03, N. 11, Jul. - Set., 2020 - http://periodicoscientificos.ufmt.br/ojs/index.php/rebeh/index
} 
sistematizando as ideias iniciais para permitir sua categorização na fase de exploração.

Posteriormente, a partir dos dados empíricos foi possível constituir as categorias e unidades temáticas na fase de exploração do material para realizar as interpretações e inferências.

$\mathrm{Na}$ análise foram construídas duas categorias fundamentadas no roteiro da entrevista e das análises das narrativas: a) Dificuldades na Saúde (Discriminações Institucionais e Auto-Hormonização) e b) Avaliação sobre o campo da Saúde (Qualidade dos Serviços de Saúde, Tratamento e Encaminhamentos Dispensados). Assim, integra-se neste trabalho 11 (onze) participantes tendo a seguinte caracterização exposta na Tabela 1:

Tabela 1 - Amostra de Participantes

\begin{tabular}{|c|c|c|c|}
\hline Nome & $\begin{array}{c}\text { Identidade de Gênero e } \\
\text { Orientação Sexual }\end{array}$ & $\begin{array}{c}\text { Cor/ Raça/ } \\
\text { Etnia }\end{array}$ & Idade \\
\hline Benivaldo & Homem Cis Gay & Negro & $\begin{array}{l}38 \\
\text { anos }\end{array}$ \\
\hline Rafael & Homem Cis Gay/Pansexual & $\begin{array}{l}\text { Amarelo } \\
\text { Asiático }\end{array}$ & $\begin{array}{l}36 \\
\text { anos }\end{array}$ \\
\hline Apolo & Homem Trans Bissexual & Negro & $\begin{array}{l}25 \\
\text { anos }\end{array}$ \\
\hline Dionísio & Homem Trans Pansexual & Branco & $\begin{array}{l}28 \\
\text { anos }\end{array}$ \\
\hline Zeus & Homem Trans Pansexual & Negro & $\begin{array}{l}21 \\
\text { anos }\end{array}$ \\
\hline Ártemis & $\begin{array}{l}\text { Mulher } \\
\text { Heterossexual }\end{array}$ & Branca & $\begin{array}{l}24 \\
\text { anos }\end{array}$ \\
\hline Pollyana & $\begin{array}{l}\text { Mulher } \\
\text { Heterossexual }\end{array}$ & Negra & $\begin{array}{l}28 \\
\text { anos }\end{array}$ \\
\hline Atena & $\begin{array}{l}\text { Mulher } \\
\text { Heterossexual }\end{array}$ & Branca & $\begin{array}{l}31 \\
\text { anos }\end{array}$ \\
\hline Júlia Flávia & $\begin{array}{l}\text { Mulher } \\
\text { Heterossexual }\end{array}$ & Negra & $\begin{array}{l}31 \\
\text { anos }\end{array}$ \\
\hline Afrodite & Travesti Bissexual & Negra & $\begin{array}{l}32 \\
\text { anos }\end{array}$ \\
\hline $\begin{array}{l}\text { Jacqueline } \\
\text { Brasil }\end{array}$ & Travesti Heterossexual & Negra & $\begin{array}{l}53 \\
\text { anos }\end{array}$ \\
\hline
\end{tabular}

Desta forma, o perfil de participantes compreende: 2 (dois) Homens Cis, 3 (três) Homens Trans, 4 (quatro) Mulheres Trans e 2 (duas) Travestis, de 21 à 53 anos, divididos entre 7 (sete) Negros, 1 (um) Amarelo Asiático e 3 (três) Brancos, 
autodeclarados enquanto a orientação sexual como 5 (cinco) Heterossexuais, 2 (dois)

Bissexuais, 2 (dois) Pansexuais, 1 (um) Gay e 1 (um) Gay/Pansexual.

Não houve participação de lésbicas, pessoas intersexos entre outras identidades mais sendo uma limitação no campo de alcance dentro das identidades da população LGBTI+ e para a compreensão das demandas específicas em saúde dessa população.

\section{RESULTADOS E DISCUSSÕES}

Analisei descritivamente as narrativas dos participantes em relação ao que tinham a dizer sobre saúde. Uma ampla gama de atravessamentos e agenciamentos acarreta movimentos diversificados na rede de atenção, visibilizando as narrativas diante dos parcos recursos disponíveis, uma vez que o processo de saúde da população LGBT ainda é permeado por discriminação e negligência criando barreiras em saúde para o acesso dessa população e para o acolhimento de suas demandas.

Assim é que trabalhei com as informações a partir de duas categorias: a) Dificuldades na Saúde (Apoio Social, Discriminações Institucionais, AutoHormonização) e Avaliação sobre o campo da Saúde (Qualidade dos Serviços de Saúde, Tratamento e Encaminhamentos Dispensados) que serão expostos a seguir.

\section{DIFICULDADES NA SAÚDE (Discriminações Institucionais e Auto-}

\section{Hormonização)}

Durante as entrevistas sobre o Processo Transexualizador e a assistência em HIV/aids os participantes relataram diversas dificuldades no que tange o acesso a saúde. As pessoas trans foram as que mais relataram dificuldades nos serviços de saúde sendo a discriminação institucional um elemento decisivo para a barreira de acesso à saúde demandando que essas pessoas procurassem formas alternativas de cuidado, desenvolvessem manobras de resistência ou até mesmo optar pela desistência de procurar uma unidade de saúde.

\footnotetext{
Não, nunca pensei em procurar, porque conversando com Apolo ele já tinha me falado que ele tinha ido em até hospital particular e não tinha dado nenhum resultado. Aí eu falei Ah, nem! (Zeus, 21 Anos)

É uma serie de questões assim, fora um atendimento normal, se eu for a um hospital para tratar uma gripe, é horrível sabe [...], eu saio de lá pior do que eu entrei, porque assim nos hospitais que eu vou, aparece seu nome assim no telão, então fica piscando. Eu espero chamar umas três vezes, finjo que não é
} 
comigo, que eu vou ao banheiro e entro no consultório. [...] Aparece, mesmo que você peça para moça, que não é ela que chama, aparece no sistema e no sistema não tem nenhum nome social e eu já fui na UNIMED pedir sabe, e eles não, depois como que a gente vai provar que é você mesmo e chega a ser bizarro isso. Fora assim, ginecologista, ginecologista é um negócio que eu não tenho para onde correr, se eu pedir pra me chamar de Apolo vai ser estranho porque vão chamar um homem para entrar no consultório de ginecologista e se eu peço para me chamar pelo nome de registro, fala um nome feminino e levanta o homem. Aí, entendeu? Aí que que eu faço quando eu preciso ir, chamo minha melhor amiga, peço para me chamar pelo nome de registro, aí ela levanta e eu vou atrás como se fosse tipo um casal sabe. Aí é aceitável né. Aí sempre entra, sei lá, a mulher vai fazer um pré-natal, alguma coisa, o marido, namorado vai. Aí só assim, é estranho porque as vezes ela tem coisas pra fazer, eu tenho que tirar ela da rotina dela, pra ela ir comigo e por mais que ela entenda querendo não é puxado né e normalmente clínica de ginecologia, obstetrícia é tudo rosa né, aí você olha foto de mulheres amamentando né, umas coisas assim, o sexismo né, a cor rosa (Apolo, 25 anos)

E eu até briguei com uma médica lá no Júlio Muller porque ela foi super grossa comigo [...]. Ela me humilhou na frente dos alunos delas. E eu saí de lá chorando (Atena, 31 Anos).

Neste quesito da discriminação, Jacqueline Brasil que descobriu ser soropositiva enquanto estava servindo a Marinha em 1991 relatou como a instituição a tratou ao saber de sua sorologia.

[,,,] eu me lembro que quando o Rio de Janeiro teve aquelas mortes das mães dos filhos, foi muito famosa da época, as mães de candelária né, que até hoje se falam nisso né. Que morreram muitas crianças, aquelas coisa toda, foi aquela chacina grande então eu mobilizei a marinha na época, o primeiro instituto naval né, no Rio de Janeiro, ali na praça da, na avenida brasil juntamente com a Fiocruz para fazer uma doação de sangue para as famílias né, então como eu já tinha articulado tudo isso, essa mobilização, pra me servir de exemplo, eu fui a primeira pessoa então a doar sangue né e com o passar do mês eu fui convocada né para me avisarem sobre o resultado do meu exame né e pra minha surpresa eu não compareci, então eu fui intimada né, aí que foi que eu fiquei com medo do resultado né, aí foi quando eu descobri da minha sorologia. [...] e a marinha ela automaticamente ela quis se livrar de mim né, na época, e me colocou né pra junta médica né e eu lembro. É por causa do HIV né, então eles me colocaram lá, eu fiquei 6 meses, quando eu voltei de 6 meses, mais 6 meses que duraram 2 anos né e nesse período de dois anos é, ida e volta, toda vez que eu tinha que entrar no quartel eu tinha que ser escoltada né, até um dia que que eles colocaram uma foto minha né, com as seguintes frases, essa pessoa é, é "aidético" e não pode entrar desacompanhado no quartel. Sabe aquele quadro que procura-se vivo ou morto? [...] Quando eu chego eu me deparo com aquela situação que me deixou constrangido pra mim passar pela portaria, ter que passar pelo quartel eu era pedido escolta do meu lado né, isso me constrangeu muito, foi a, acho que foi a pior fase da minha descoberta sobre a sorologia, o preconceito que existia naquele momento né, me senti sozinho, sendo escoltado, como se eu fosse um marginal. (Jacqueline Brasil, 53 anos) 
Jacqueline Brasil expõe o paradigma da segurança pública no Brasil em relação à população LGBT em que, na maioria das vezes, tem ficado à mercê da insegurança, sem garantias de proteção e sendo tratada com certo alheamento e discriminação. Em relação à discriminação que Jacqueline passou, cabe salientar que chamar alguém de “aidético" significa narrar que essa pessoa é a própria doença, ou seja, constrói-se pelo campo da linguagem em uso um novo contexto para o HIV e para a pessoa soropositiva que seria concebida como amaldiçoada ou que tem mau agouro.

Conforme exposto pelo Grupo de Incentivo à Vida (GIV), o termo toma a intenção de estigmatizar e injuriar as pessoas com sorologia positiva para o HIV, tornando-as sinônimas da doença. Desumaniza e destitui-se a pessoa de sua cidadania, passando a ser vista como uma pessoa condenada, sentenciada a morte e por ser assim, sem muitas possibilidades de vida.

Enfrentando diversos estigmas e discriminações, a população trans tem dificuldades inclusive para buscar serviços que lhes são referência como o PT. Neste sentido, Atena foi a única participante que conseguiu ter acesso ao PT e realizou a cirurgia de transgenitalização expondo que "o funcionamento é você buscar informação e ajuda por conta própria. E não existe uma equipe capacitada para atender essa demanda" (Atena, 31 Anos).

Uns cinco anos, o processo. E meu professor da faculdade, ele falou pra mim, pra você fazer a cirurgia de readequação sexual, é a partir dos 25 anos. Eu gente que palhaçada. Vou começar a transar depois dos 25 anos porque as transexuais mesmos, as zero que eles falam, transexuais mesmo, que são transexuais que tem dificuldade por isso que fazem a cirurgia, elas não conseguem se relacionar com os homens, devido a seu órgão. E aí você fala cara, e eu vou usufruir tudo isso depois dos 25 anos, ter relação com homem, é complicado. Imagine o baque que não vai ser para essa mulher deitar com o homem, transar com ele, ter confiança e ficar com ele e não se sentir mal por estar usando, por estar mostrando seu órgão. (Atena, 31 Anos).

Uma questão abordada por todas as pessoas trans das pesquisas diz respeito a Autor-Hormonização6 pela dificuldade de conseguir a hormonioterapia pelo no SUS relatando a insegurança que é ter que recorrer a tal prática:

6 É considerado Auto-hormonização a prática do uso do hormônio por conta própria, sem acompanhamento de um profissional de saúde (ALMEIDA, 2018) enquanto a hormonioterapia se configura como a prática do tratamento hormonal prescrito e com devido acompanhamento médico (BRASIL, 2013)

Vol. 03, N. 11, Jul. - Set., 2020 - http://periodicoscientificos.ufmt.br/ojs/index.php/rebeh/index 
Você não sabe o que que é que você tá aplicado, é made in paraguay. Às vezes é óleo mineral que você ta aplicando e você não sabe. Porque ela é oleosa, então eles podem colocar qualquer tipo de óleo. No rio, mês passado eles tavam até tratando na conferência sobre a hormonização ilegal e que era tão arriscado quanto as bombadeiras né e a gente sabe de tudo isso. Eu sei que eu não posso fazer isso, porém eu vou fazer o que? Vou ficar sem hormônio? Entendeu? Da mesma forma que agride eu tomar, da mesma forma agride se eu parar do nada entendeu? (Apolo, 25 anos).

Sempre tomei hormônio por conta própria assim, de início eu tinha esses grupos de Orkut, depois passou para o Facebook né e ela a gente se informava, trocava informações sobre que hormônio está tomando então sempre foi um uso indiscriminado né. Nunca tive um acompanhamento endocrinológico, até porque as duas vezes que eu procurei endocrinologista pra ver eles falaram que não queria me receitar isso. Porque poderia dar muitos problemas pra mim no futuro e seria ele que teria me receitado, então assim. Eu tinha muita dificuldade. [...]. Essas coisas, mas assim a hormonização sempre foi feita de forma indiscriminada mesmo, pela maioria de nós." (Afrodite, 32 Anos)

Ainda sobre a hormonização, uma participante traz uma questão importante para que esta demanda em saúde seja de fato um tratamento realizado pelo SUS visto que o uso sem acompanhamento médico certamente pode gerar alguns eventos adversos que precisam ser monitorados como, por exemplo, questões de ordem neurológicas, emocionais, de humor e psicológicas.

Não, foi lá na farmácia que o cara falou assim óh, você pode aplicar aqui, posso! Porque tem farmácia que não aplica né. [...]. E aí fui aplicando, no começo assim eu aplicava sempre com ele [...]. Até que eu peguei outro e eu acho que o outro nem percebeu se eu era transexual ou não. Porque chegou um momento da minha vida que as pessoas tem dúvida né, sabe ou não. $\mathrm{O}$ que mais condena pelo que eu já vi das pessoas falando é minha voz, ah sua voz é grossa, então eu percebi. Eu ah tá. Eu fico com raiva disso, eu quero muito ver se eu consigo afeminar mais mas enfim, e aí eu, chegou fevereiro eu comecei a aplicar a vacina de 15 em 15 dias. Aí eu comecei a ficar louca do hormônio, fiquei depressiva, fiquei alegre, fiquei triste, fiquei chorando, com raiva. E a cada dois em dois dias uma reação de humor diferente. Nossa, agora eu to super de boa. Faz uns dois meses que eu não aplico né. Deu tempo de já diminuir essa quantidade de nível hormonal. Mas tava muito complicado, eu tava muito louca. Você não tem noção. E o que eu precisava fazer isso. Eu precisava afinar, pra ficar mais feminina o meu corpo né. Tanto é que eu ganhei mais bunda, a perna ficou mais gordinha, o braço ficou mais molinho né. (Ártemis, 24 Anos)

Devido às diversas dificuldades na saúde sobretudo para o acesso da hormonioterapia, as participantes demonstraram que saúde também se produz na coletividade, entre seus pares, na rede de socialidade (VERGUEIRO, 2016). É nessa rede de cuidado que se inscrevem (re)existências a um sistema que parte da perspectiva sexista e cisgênera binarista para decidir, desde saberes médicos, sobre os processos de

Vol. 03, N. 11, Jul. - Set., 2020 - http://periodicoscientificos.ufmt.br/ojs/index.php/rebeh/index 
vida das pessoas trans ainda que pudessem estar fazendo alguma contravenção, mas o

Estado já estava sendo infrator com elas há muito tempo visto que o SUS constitucional legitima em seu Art. 196 que:

A saúde é direito de todos e dever do Estado, garantido mediante políticas sociais e econômicas que visem à redução do risco de doença e de outros agravos e ao acesso universal e igualitário às ações e serviços para sua promoção, proteção e recuperação (BRASIL, 1988).

Desta forma, percebe-se que na prática esse artigo não é respeitado sendo a saúde aplicada de forma seletiva e operando num lógica cisgênera e heterossexual até mesmo nos serviços de referência do PT. Afrodite expõe seu percurso no serviço de referência em Brasília relatando as dificuldades na unidade:

Em Brasília o HGUB ele oferece a terapia psicológica, ela é acompanhada com um psiquiatra e um psicólogo. E em Brasília tem muito mais aparato que em Cuiabá né, lá ainda tem um centro de referência que trabalha justamente com as questões trans também, que era onde que eu conseguia os meus hormônios assim, eles não podiam dar os hormônios, mas as trans articuladíssimas lá dentro sempre tinha um tráfico de hormônio de graça. Sacou, pra nós? E sempre rolava umas caixinhas pra nós, que elas distribuíam, mas aquilo né. Uma coisa muito nossa né, não existia. A única coisa que o HGUB oferecia era o acompanhamento endocrinológico, ele não oferecia o hormônio, até tive uma briga com ela porque eu acabei minha terapia com 18 anos, é com 18 anos e eu me questionava já nessa época sobre a minha sexualidade, se era bi, hétero, homo ou não. O que que eu era? Então assim, eu já tinha visto já que eu também não era uma transexual normal. Sacou então, assim, no dia da minha entrevista final com a psicóloga que ela é a detentora do poder né, que vai dar o visto na sua cirurgia, e foi quando eu não fui aprovada, pela primeira vez que eu passei por esse teste né, passei um ano fazendo a terapia, ela disse que eu não me enquadrava ao caso trans porque se eu tinha tendências bissexuais, isto não era coisa de mulher. Nossa senhora, vai se fuder né. Quebrei o pau com a mulher. Porque assim, ela queria, ela tinha um modelo transexual ok. Que hoje foi um questionamento que eu me fiz e faço mais ainda de que esse processo transexualidor né, ele acaba te encaixando novamente na norma hererocisnormativa e que você ser bissexual é você fugir dessa regra, então até o próprio governo, não sei se era uma coisa particular do governo porque eu fiz terapias em hospitais né, ou se era uma coisa particular daquela psicóloga de Brasília ou se não é uma ordem que ela recebe para que seja assim. Não tenho certeza né, como eu só fiz lá. E aí a gente teve uma briga ferrenha obviamente por tudo isso e nisso se passaram, não consegui a minha cirurgia sacou, até conversei com algumas amigas minhas transexuais que também faziam terapia na época. E elas falaram. Nossa 'Afordite' como você é burra, você tem que falar o que eles querem ouvir aqui. Não é o que você é de verdade. Ou o que você deixa de ser, é o que eles querem ouvir. E eu falei, porra. Só que eu não pensei que fosse assim sacou. Imaginava que eu poderia falar o que eu sinto, o que eu penso, o que eu acho. Aí ela não aí, te cortaram a cirurgia. Tudo bem! Passaram-se alguns anos eu retornei pra Brasília e quando eu retornei eu fui novamente fazer essa mesma terapia. Um ano de terapia né. Só que eu já tava muito mais feliz né sacou, as pessoas que estava lá não me reconheciam. [...]

Vol. 03, N. 11, Jul. - Set., 2020 - http://periodicoscientificos.ufmt.br/ojs/index.php/rebeh/index 
E aí foi quando eu terminei e concluí. Só que essa lista, eu acho que é uma lista que ela vive no limbo, no além sacou, porque você não sabe o que se passa nesta lista. Quantas pessoas são, se tem pessoas na sua frente ou não sacou? Então assim, é muito problemático, uma amiga minha acabou a terapia depois de mim e ela já operou já. E eu não operei até hoje né. Não também que hoje eu também ache que eu queira operar, porque hoje eu até tenho os meus receios com relação a cirurgia, nem sei se eu quero operar, [...] eu não sei se eu tenho essa convicção toda da cirurgia sacou, porque eu me questiono se até pra eu ser uma mulher trans eu preciso de fato ter que operar? É isso? Sacou? (Afrodite, 32 Anos).

Assim como Afrodite, Dionísio expõe dificuldades semelhantes no serviço de referência para o PT em São Paulo:

Eu fiz várias terapias durante a vida assim, depois desse processo também, mais consolidado eu fiz com dois profissionais e muito louco porque, um da psiquiatria só que assim, o cara é uma figura muito importante lá do PROSEX, do hospital das clinicas, teoricamente é uma pessoa que a gente pow, você ta lá no olho do negócio, a gente pressupõe que né. E esse cara veio com papos assim bem, aquelas coisas que a gente sempre ouve, você queria arrancar a sua vagina fora? Não brother, obviamente que eu não queria arrancar minha vagina fora, porque eu não sou louco. Se eu fizesse isso eu ia morrer. Então sabe, umas coisas muito, como você se sente em relação ao seu peito? Se eu pudesse, eu teria arrancado fora, como é o mesmo o caso eu não posso. Ele não ta me conhecendo, ele tinha 50 minutos pra me conhecer e ele focou em detalhes que acho que são desnecessários, era mais pra testar mesmo se eu era ou não uma pessoa trans entendeu? Bem técnico, bem técnico. E aí assim, você já pensou em se matar? Ah eu já pensei em me matar em 2012, eu tava muito bem e aí eu sentei no meu sofá e falei cara, se eu morresse agora ia ser de boa, ia ta tudo bem, ta não sei o que, mas assim cara, eu pensei isso 5 minutos e dispensei sabe, não era uma coisa assim nossa, cheguei a conclusão efetivamente de que eu queria fazer isso e aí o cara já falou não, então você é uma pessoa que ta com depressão tendências suicidas, precisa passar por um processo de readequação. E eu assim tipo, pensando né. Então qualquer coisa que eu te falar é isso que você vai escrever no seu relatório e isso vai ser entendeu. [...] Então, você ta entendendo como que foi? Aí assim, aí minha mãe falou e aí você quer voltar pra São Paulo, quer fazer parte do PROSEX? Falei cara, não. E aí minha mãe falou, você sabe que você não vai conseguir o processo, sabe, você não vai conseguir fazer a cirurgia. Eu não tenho grana pra pagar, você não tem grana pra pagar. Eu não sei como que vai ser a hormonização. Eu falei cara, eu não vou ficar, eu não vou me institucionalizar de novo sabe? Eu não vou me enquadrar num formulário que não me representa, saca? Eu li todos os textos das leis e diretrizes né e são ridículos, são técnicos, são valores de cirurgia sabe que cara? Aí você dá esse texto ao funcionário do SUS trabalhar entendeu? Como? Como? É inviável, é inviável. Mas enfim. Rolaram essas procuras né, mas é isso, eu acho que tem um momento que a gente já se desconstruiu tanto que a gente não consegue mais saca?" (Dionísio, 28 Anos).

Percebe-se através do relato de Afrodite e Dionísio a imposição de uma cisgeneridade compulsória que atravessa às práticas dentro do PT a partir de uma lógica 
binária de gênero. É importante destacar que as questões trans dizem respeito a uma questão relacionada à identidade de gênero e não de orientação sexual. Tal como a heterossexualidade compulsória (RICH, 2010) está como norma para as orientações sexuais, a cisgeneridade compulsória está como norma para as questões de gênero (BAGAGLI, 2016).

Sendo assim, como se ordena em nossa sociedade que o ideal é ser heterossexual, também se veicula de forma análoga que as pessoas devem ser cisgêneras (CAZEIRO, SOUZA \& BEZERRA, 2019). Em consequência dessa violência é que as pessoas trans são especialmente vulneráveis a depressão e ao suicídio demandando atenção em saúde mental que compreenda esses fenômenos discriminatórios como promotores de sofrimento, inclusive psíquico. Ademais, entender conforme afirma a Bruna Benevides (Sec. de Articulação Política da ANTRA - Associação Nacional de Travestis e Transexuais) que :“As pessoas trans não se suicidam porque são trans. Elas se suicidam porque o resto da sociedade não as trata como se fossem pessoas" (BENEVIDES, 2018, p. 2). Neste quesito da saúde mental, Apolo reflete sobre o as determinações do PT:

Do processo transexualizador eu acho que não deveria ser obrigatório essa consulta, de dois anos, deveria ser assim, não deveria ser uma patologia, deveria ser assim, eu sou uma pessoa trans, eu não tenho, eu não preciso de acompanhamento psicológico, eu to bem comigo mesmo, eu vou fazer uma cirurgia beleza, mas de repente eu quero um atendimento, pré ou pós sei lá como uma pessoa cis, deveria ser um auxilio ali facultativo. Eu então acho que as pessoas iriam buscar mais atendimento psicológico pra se sentir saudável mentalmente e não porque é obrigatório trocar nome, é obrigatório pra fazer cirurgia, porque acaba que você chega lá é uma grande mentira. Você tem que mentir que você odeia o seu corpo, você tem que falar isso, você tem que falar aquilo, porque senão o psicólogo ele não te dá o laudo, se por exemplo eu chegar lá e eu falar que eu sou um homem trans e que eu faço sexo com penetração, vai falar, jamais, você não é, que direito a pessoa tem de dizer o que eu não sou o que eu sou sabe? É mas na hora de cobrar meu imposto, na hora de querer meu voto, eu sou perfeito pra isso sabe, minha saúde mental ta perfeita" (Apolo, 25 Anos).

Pensar sobre as práticas de profissionais no contexto da promoção de saúde das pessoas trans nos leva à necessidade de considerar os atravessamentos epistemológicos, éticos, estéticos e conceituais, micro e macro políticos, intersubjetivos e socioculturais que se fazem presentes de modo a construir práticas que fortaleçam os direitos e a cidadania dessa parcela da população que corriqueiramente segue enfrentando barreiras, 
estigmas e invisibilidade na atenção à saúde (Sales, Lopes \& Peres, 2016; Pocahy, 2016). No PT, o que se evidencia, inclusive, na nomeação, enfatiza a genitália quando, em contraponto, justamente, é preciso compreender que a cirurgia é uma parte de várias no que tange ao processo de transição de gênero.

embora a atenção da mídia e a dos estudiosos tenham enfocado obsessivamente a cirurgia, esta é a única parte do tratamento médico, o qual é apenas uma parte da transição. Uma enorme quantidade de outras tarefas é necessária. Isso inclui levantar fundos; ter apoio pessoal, cuidados pósoperatórios, documentação legal; encontrar moradia; lidar com crises de relacionamentos; lidar com locais de trabalho ou arranjar trabalho; lidar com mudanças corporais; obter reconhecimento social; lidar com a hostilidade. Qualquer um desses fatores pode se tornar central (Connell \& Pearse, 2015, p. 217).

Bento e Pelúcio (2012, p. 576), apontam que questionar o protocolo do Processo Transexualizador "nos termos em que vem sendo implementado, é encarar a patologização do gênero e colocá-lo na arena de debates, situando-o como categoria científica, e por isso mesmo, histórica, o que significa considerar também seu caráter político". Nesse sentido, a saúde (inclusive a mental) precisa se amparar pela perspectiva da trans autonomia. Por isso, o tempo da terapia e, inclusive, o direito de não se submeter a um tratamento psicológico como parte do Processo Transexualizador deveria ser preservado. Uma prática psicológica pautada pela produção de saúde atenta à singularidade das demandas é fundamental para não incorrer na patologizacão das expressões e identidades de gênero das pessoas trans.

AVALIAÇÃO SOBRE O CAMPO DA SAÚDE (Qualidade dos Serviços de Saúde,

\section{Tratamento e Encaminhamentos Dispensados)}

A partir dos relatos sobre a saúde foi possível perceber que as narrativas caminhavam em tom de denúncia e avaliação pelos participantes em relação ao tratamento dispensado e a qualidade dos serviços que buscaram para terem suas demandas acolhidas. Nesse sentido, Atena relata um pouco do processo cirúrgico da transgenitalização:

Eu avalio péssimo, é péssimo, péssimo, péssimo. Se você não tiver Q.I. né legal, uma comunicação, não for atrás, você tem que ter força de vontade aqui em Cuiabá senão você não consegue, se você não for atrás [...] O ruim, o ruim desse processo da cirurgia, por você não ta bancando, ta pagando, é tudo muito duvidoso, você não tem certeza de nada, você não tem certeza mesmo se você vai fazer a cirurgia, você não tem certeza se vai acontecer alguma

Vol. 03, N. 11, Jul. - Set., 2020 - http://periodicoscientificos.ufmt.br/ojs/index.php/rebeh/index 
B.O. na sala de cirurgia, então tipo assim, tudo poderia acontecer de eu não fazer a cirurgia, cheguei lá, tava muito depressiva, conversei com a médica, eu falei, eu preciso fazer a cirurgia porque eu larguei escola né, larguei a faculdade, larguei tudo, tenho que fazer esse trem porque senão voltar pra lá ter que enfrentar tudo, aquela briga com os professores tudo e não fazer a cirurgia. Ela falou, não Eliza, vamos ver o que vai. Eu lembro que eu tava na sala de cirurgia e o médico falou assim, ta faltando isso, ta faltando aquilo. Eu só lembro que eu apaguei e eu não lembro muito bem, eu só lembro dessa confusão de talvez eles não fazerem a cirurgia. Eu lembro deles ah vamo olhar, depois eu lembro de apagar... Aí eu acordei já na sala de recuperação né, que eles deixam você lá por bastante tempo pra ver se você não vai alguma reação, se vai ter parada cardíaca ou não, aí a enfermeira viu deu tudo certo, tipo ela com o sorrisão e eu com aquele monte de coisa na cabeça. Que é aquele cara, o que aconteceu, fiz a cirurgia. $\mathrm{E}$ aí ela, não, deu tudo certo, você agora é uma nova mulher. Aquelas coisas todas que eles falam. Parece coisa de conto de fada entendeu. [...] você tem de se adaptar. [...] Então tipo assim, é super importante você ta movimentando aquele orifício pra manter a profundidade. E como eu mudei [de molde], então imagine, o quanto que eu perdi de profundidade. É revoltante. Todas as transexuais ficam revoltadas com a profundidade. Então se a pessoa for fazer e tiver condições, compra o [molde] de acrílico. Eu me arrependo até hoje de não ter ficado com aquele acrílico. Eu falei puxa, porque que eu fui devolver. Devia ter enrolado ela até na hora de ir embora. Depois que começou a sangrar, de eu conseguir a profundidade grande que entrou todo de acrílico, foi legal. Mas assim, dói, doí muito. Mas você tem que fazer, tem que dilatar. E você tem que fazer aquilo duas vezes por dia, aí depois vai diminuindo entendeu? Então é muito doloroso. Você tem que se amar muito, você tem que querer muito aquilo (Atena, 31 Anos).

A avaliação realizada por Atena remete às entrevistas realizadas com as profissionais que trabalhavam diretamente com o protocolo do Processo Transsexualizador via Tratamento Fora Domicílio (TFD) na Coordenação de Regulação em Cuiabá-MT. As entrevistas foram realizadas com duas assistentes sociais, responsáveis por cuidar e encaminhar os processos de solicitação de PT para os ambulatórios e hospitais de referência, além de articular todos os recursos necessários para a execução do mesmo.

Durante as entrevistas, as profissionais não permitiram a gravação da entrevista em áudio e por isso não foram incorporadas no estudo. Além disso, alegaram que não poderiam contribuir com a pesquisa, pois não tinham tido contato com a temática em sua formação. Segundo as profissionais, não se falava neste assunto, pois este tema era recente e como não faziam atendimentos com as pessoas trans não precisariam estar cientes da temática visto que apenas trabalhavam no encaminhamento dos pedidos e solicitações. 
No que tange ao laudo da transexualidade, as profissionais alegaram que concordavam justificando que era necessário para que as pessoas trans conseguissem a cirurgia e pudessem fazer todo o processo, pois assim como em outros casos, o diagnóstico é bom. Desconheciam as reivindicações do movimento trans pautando-se sempre pelas vias discriminatórias. Na avaliação de uma assistente social sobre a eficácia do TFD para o Processo Transsexualizador, ela alegou que há falta de recursos para a efetivação do processo e que muitas vezes, por conta das solicitações serem muitas, algumas unidades de referência não abrem vaga para oferta gerando uma grande fila de espera.

Uma das pessoas procuradas para a pesquisa, trabalhadora no serviço, afirmou que pessoas trans eram "loucas", pois seria um absurdo fazer a modificação dos órgãos genitais. Alegou que se as pessoas trans que entrassem com as solicitações não retornassem presencialmente para saber sobre o andamento do processo, ele não prosseguia com o andamento dos processos deixando-os parados na instituição. Esta pessoa não foi incluída na pesquisa, sendo respeitada sua negação em fazer parte das entrevistas. Por este motivo é que essas informações relatadas aqui são provenientes do diário de campo.

A partir dessa situação pode-se perceber como a saúde LGBT, especialmente a saúde das pessoas trans ainda é relegada a uma categoria diagnóstica, anormal e arbitrária. Neste sentido, Apolo e Afrodite trazem importantes reflexões para concepções mais integrais em saúde:

E outra, quer tratar como doença, beleza, vamo tratar como doença então, mas cadê o tratamento pra isso? Entendeu? Fica nessa, não dá o tratamento adequado, mas quer tratar como doença. Aí não quer tirar como doença porque, aí tem gente que fala, ah mas assim vai ficar mais difícil de conseguir a cirurgia né, porque daí não é doença a gente não vai conseguir a cirurgia. Gravidez não é doença. Grávida chega pra fazer um parto no SUS e consegue. Não é questão de patologia, é questão de saúde. E o que que é saúde? É só saúde física? É só saúde mental? Não, é um conjunto né, se você for olhar o que que é, o que significa ser saudável né, integra um monte de conceito né. E as pessoas tem que parar de achar, ah, não tenho um CID, não vou conseguir um atendimento. Só aqui, sensibilização né. Tem que humanizar mais o atendimento né, porque não adianta tipo tirar a patologia mas continuar os profissionais assim da forma que ta, aí eu concordo que vai ser mais puxado ainda, que o pessoal vai falar, se bem ainda vai demorar ainda pra tirar isso, por mais que tire a patologia agora, vai demorar alguns anos (Apolo, 25 anos)

Ah, o processo meu corre em Brasília porque o pessoal do núcleo de referencia de lá, juntou todas nós transexuais, que era em torno de umas 20

Vol. 03, N. 11, Jul. - Set., 2020 - http://periodicoscientificos.ufmt.br/ojs/index.php/rebeh/index 
transexuais e fez um processo conjunto. E eu não sei como anda ainda. Eu lembro que da ultima vez que eu fui lá eu tive que levar documentos novos pra eles. Mas é isso, é um processo conjunto para a mudança. Mas que hoje em dia, é, vale-se relembrar né, duas coisas: Uma que a lei que mudou, que agora dificultou bastante a questão da cirurgia, que nós temos que operar no lugar em que vivemos né. Então no caso aqui de Cuiabá, o Júlio Muller que teria que ter essa assistência. Isso é a forma do governo obrigar a se ter mais médicos nessa área, porém não é uma área que os médicos estão estudando sacou? Então fazer isso, ou você jogar todas as transexuais para uma cidade da qual opera, sacou? Porque é isso que vai acontecer. Elas vão migrar pra operar né. As que sentir necessidade da cirurgia, porque elas não vão ficar esperando velho a cidadezinha lá do interior de guaporanga, sei lá, abrir, ter um. Não vai acontecer, não vai ter mão de obra especializada pra fazer essa cirurgia em todo Brasil. (Afrodite, 32 Anos)

Além disso, no que tange à assistência em HIV/aids, os participantes trouxeram em tom de denúncia o impacto dos cortes nas políticas de saúde para a falta de medicamento antirretrovirais demonstrando à negligência com seus tratamentos que são vitais, além de sugerirem que essa precarização seja uma forma mascarada de higienização social nesse campo:

Bem, de início os medicamentos sempre estavam ali para todo o momento só que muitos colegas começaram quando foram pegar, começou a faltar [...] e isso foi até para televisão para ver o que, o que estava acontecendo, até que hoje, não vou dizer que está $10 \%, 100 \%$, mas melhorou um pouco. (Benivaldo, 38 Anos)

[...] é um SAE que ainda ta começando ali no Alecrim, então falta muita coisa ainda e...

A: Você sabe se alguma vez já faltou remédio, alguma coisa assim?

B: Falou, faltou. Vish! Faltou por dois meses. Eu fiquei doidinho (risos)

A: Sério?

B: Faltou por dois meses, eu fiquei sem medicação por dois meses.

A: Mas isso não prejudicou seu tratamento?

B: Não, não, não, não prejudicou porque o meu médico arranjou. Mas falta, ficou faltando ali no SAE e aí até eu reclamei, fiz reclamação e tudo mais (Rafael, 36 Anos)

Olha, eu não sei, eu não sei se eu to sendo muito dramático mais eu acredito muito na higienização social, a mesma coisa que aconteceu na década de 80 , então eu acho que isso é uma higienização mascarada sabe, porque quem mais vai sofrer com esse desmonte é os pobres, os gays, lésbicas, héteros, transexuais, travestis, que ta aqui na camada debaixo, então havendo esses desmontes, essas privatizações, quem vai sofrer somos nós, não são as que tão lá em cima não então é uma higienização mesmo, mascarada sim e até mesmo descarada também. (Júlia Flávia, 31 Anos)

E para finalizar, Jacqueline Brasil expõe uma importante pauta para se pensar às questões de saúde estando vinculada aos processos de cidadania, trabalho, habitação, renda, alimentação entre outros direitos previstos na constituição (BRASIL, 1988).

Vol. 03, N. 11, Jul. - Set., 2020 - http://periodicoscientificos.ufmt.br/ojs/index.php/rebeh/index 
Olha, precisamos avançar, eu acho que a medicação principal não é só a medicação, eu acho que você tem que trabalhar as questão do social, da alimentação, do bem-estar, da autoestima né e a saúde ta aí, é a gente tem avançado nos coquetéis, as novas tecnologias de prevenção, ela tem se aprimorando mas precisa ter, abrir mais acessos, ter mais acessibilidade pelas pessoas porque infelizmente ainda falta medicação, ai vem a questão do, é, financeiro, que as pessoas visam mais o lado financeiro do ser humano né, cada vez mais caro né, impossibilitando e que a gente precisa ta dialogando, eu acho que o avanço é esse, é com o diálogo com a sociedade civil, a gente precisa ta dialogando, a gente precisa reconhecer o nosso lugar enquanto cidadão, enquanto usuário e lutar pelo um SUS melhor. (Jacqueline Brasil, 53 Anos)

Com base nisto, vale lembrar que a saúde está inserida também no artigo XXV na Declaração Universal dos Direitos Humanos (1948) definindo que "toda pessoa tem direito a um nível de vida suficiente para lhe assegurar e à sua família a saúde e o bemestar, principalmente quanto à alimentação, ao vestuário, ao alojamento, à assistência médica e ainda quanto aos serviços sociais necessários" (ONU, 1948, p. 6)

Portanto, o direito à saúde não se restringe apenas a um atendimento hospitalar ou em serviços e unidades básicas. Ainda que o acesso a estes serviços tenha relevância sendo um direito fundamental, o direito à saúde implica também na garantia ampla e plena de qualidade de vida em cooptação com outros direitos básicos, como educação, saneamento básico, cultura e segurança. Ou seja, o direito à saúde é indissociável do direito à vida embasados por valores de igualdade entre as pessoas que não tem sido assegurado às pessoas LGBT como pôde ser percebido nos relatos aqui expostos.

Grosso modo, essas reivindicações revelam a interdição da categoria de humanidade no qual a cidadania, os direitos básicos - e ditos inalienáveis - são cerceados constantemente.

\section{CONSIDERAÇÕES FINAIS}

No campo próprio à saúde da população LGBT, é necessário que os princípios de universalidade, integralidade e equidade constitutivos do SUS sejam materializados em políticas públicas que promovam o enfrentamento das consequências excludentes da LGBTfobia e da cis-heteronormatividade, que levam profissionais de saúde a atenderem essas pessoas como se fossem pessoas cis e heterossexuais conformados às normas binaristas de gênero, o que gera situações graves de discriminação e preconceito. Do contrário, continuarão a existir barreiras simbólicas, morais e estéticas que impedem o 
acesso da população LGBT a serviços públicos de saúde de qualidade, livres de preconceito, discriminação e exclusão, especialmente em relação às pessoas trans que questionam de maneira mais profunda e direta os binarismos de gênero conforme os relatos descritos. As mudanças em curso não são simples e parecem não ocorrer na velocidade desejada por estas pessoas que buscam atenção, acolhimento e cuidados.

Passados 40 anos da epidemia de HIV, as LGBT têm um acesso maior no SUS e é compreendida como uma população que tem outras demandas em saúde para além do HIV/aids, e no caso das pessoas trans para além do Processo Transexualizador também, conforme a Política Nacional de Saúde Integral LGBT (BRASIL, 2013). Desta forma, é necessário falar da saúde de pessoas LGBT a partir de suas demandas e não sobre uma perspectiva da doença/patologia e suas vítimas conforme ressalta Laurentino (2015) e que pode ser observado nas entrevistas.

Deixando as reflexões em aberto, espera-se que a continuidade do diálogo, da sensibilização e das lutas contra as desigualdades e violências possam reconduzir e superar racionalidades opressoras. Ações que já começaram a ser desempenhadas, das quais não sou protagonista. Não pretendo dar o parecer científico final, mas adicionar elementos e reflexões que dêem lugar para novas articulações, fora do limbo em que se encontram, (trans)formando em ecos de força que abalem as estruturas fincadas em nossas relações políticas e sociais para a concretização de uma saúde e sociedade mais justa, democrática e igual para todas as pessoas.

\section{REFERÊNCIAS}

ALBUQUERQUE, G. A. et al. "Homossexualidade e o direito à saúde: um desafio para as políticas públicas de saúde no Brasil". Saúde Debate, Rio de Janeiro, v. 37, n. 8, 2013.

ALMEIDA, A. S. 2018. Vidas em espera: uma etnografia sobre a experiência do tempo no processo transexualizador. Dissertação de Mestrado em Antropologia Social, Universidade Federal de Goiás.

ARAGUSUKU, H. A. \& LOPES, M. A. S. "Políticas públicas e cidadania LGBT em Mato Grosso: Uma década de avanços e retrocessos (2007-2017)". Sex., Salud Soc, Rio de Janeiro, n. 29, 2018.

BAGAGLI, B. P. "A diferença trans no gênero para além da patologização". Revista Periodicus, Salvador, n. 5, p. 87-100, 2016.

BARDIN, L. Análise de conteúdo. São Paulo: Edições 70, 2011

Vol. 03, N. 11, Jul. - Set., 2020 - http://periodicoscientificos.ufmt.br/ojs/index.php/rebeh/index 
BASTOS, F. I. Aids na terceira década. Rio de Janeiro: Editora FIOCRUZ, 2006.

BENEVIDES, B. Precisamos falar sobre o suicídio das pessoas trans! Disponível em: <https://antrabrasil.org/2018/06/29/precisamos-falar-sobre-o-suicidio-das-pessoastrans/>. Acesso em: 05 de outubro de 2020

BENTO, B. \& PELÚCIO, L.. "Despatologização do gênero: a politização das identidades abjetas". Revista Estudos Feministas, v. 20, n. 2, p. 559-568, 2012.

BRASIL. Conselho Nacional de Combate à Discriminação. Brasil sem homofobia: programa de combate à violência e à discriminação contra GLTB e promoção da cidadania homossexual. Brasília, DF: Ministério da Saúde; 2004.

BRASIL. Constituição da República Federativa do Brasil de 1988. Brasília, DF: Presidência da República, [Constituição (1988)]. Disponível em: http://www.planalto.gov.br/ccivil_03/constituicao/constituicao.htm. Acesso em: 28 de setembro de 2020.

BRASIL. MINISTÉRIO DA SAÚDE. Departamento de DST, AIDS e Hepatites Virais. História da Aids. Ministério da Saúde, Brasília. 1982. Disponível em: http://www.aids.gov.br/pt-br/centrais-de-conteudos/historia-aids-linha-do-tempo.

Acesso em: 15 de agosto de 2020

BRASIL. MINISTÉRIO DA SAÚDE. Portaria No 158, de 4 de Fevereiro de 2016. Redefine o regulamento técnico de procedimentos hemoterápicos. Brasília, Diário Oficial da União, 05 fev. 2016. Disponível em: http://bvsms.saude.gov.br/bvs/saudelegis/gm/2016/prt0158_04_02_2016.html. Acesso em: 18 de junho de 2020

BRASIL. Política nacional de saúde integral de Lésbicas, Gays, Bissexuais, Travestis e Transexuais. Brasília: Ministério da Saúde, 2013

BRASIL. Portal de Saúde do Governo Federal. Processo transexualizador no SUS. Disponível em: <http://portalsaude.saude.gov.br/index.php/oministerio/principal/secretarias/1174-sgep-raiz/lgbt/21885-processo-transexualizador>

Acesso em: 28 de setembro de 2020

CANGUILHEM, G. O normal e o patológico. Tradução de Maria de Threza Redig de C. Barrocas e Luiz Octávio F. B. Leite. 5. ed. Rio de Janeiro: Forense Universitária, 2002.

CAZEIRO, F.; SOUZA, E. M. F.; BEZERRA, M. A. "(Trans)tornando a norma Cisgênera e seus derivados". Rev. Estud. Fem., Florianópolis, v. 27, n. 2, p. 1-12, 2019.

CAZEIRO, F. Histórias Posit(hiv)as de Gays e Pessoas Trans: Dos Estigmas à Cidadania. Dissertação (Mestrado em Psicologia) - Centro de Ciências Humanas, Letras e Artes, Universidade Federal do Rio Grande do Norte; 2019. Natal, p. 174. 2019

CAZEIRO, F.; NOGUEIRA DA SILVA, G. S. ; SOUZA, E. M. F. "Necropolítica no campo do HIV: Algumas reflexões a partir do estigma da aids". Ciênc. saúde coletiva, Rio de Janeiro, 2020. 
CAZEIRO, F.; GALINDO, D. C. G. ; GUIMARAES, R. S. ; LEMOS de SOUZA, L. "Processo transexualizador no SUS: questões para a Psicologia a partir de itinerários terapêuticos e despatologização". Psicologia em Estudo, Maringá, No prelo.

CFP. Nota técnica sobre processo transexualizador e demais formas de assistência às pessoas trans. 2013. Brasília, DF: Conselho Federal de Psicologia.

DANIEL, H. \& Parker, R. AIDS: a terceira epidemia. São Paulo: Iglu Editora, 1991.

FACCHINI, R. "Entre compassos e descompassos: um olhar para o "campo" e para a "arena" do movimento LGBT brasileiro". Revista Bagoas, n. 04. Natal: UFRN, 2009

Figueiredo, P. P. et al.. "A saúde sob a perspectiva da cidadania". Rev. Min. Enferm., v. 13, n. 2, 2009.

FONSECA, A. F. "Políticas de HIV/Aids no Sistema Único de Saúde: uma busca pela integralidade da atenção". In: Escola Politécnica de Saúde Joaquim Venâncio (org.). Textos de apoio em políticas de saúde. Rio de Janeiro: Editora da Fiocruz, 2005. p. 183-205.

FREIRE, P. Pedagogia do Oprimido. $45^{\mathrm{a}}$. ed. Rio de Janeiro: Paz e Terra, 2005

FREIRE, P. Política e Educação. $5^{\circ}$ ed. São Paulo: Cortez, 2001.

GALINDO, D. et al.. "LGBTs e Gênero Banidos? Notas Genealógicas Sobre Projetos De Lei No Brasil”. Psicologia em Estudo, Maringá, v. 22, n. 2, p. 253-265, 2017.

GIV. Grupo de Incentivo à Vida. Não para a palavra "Aidético". GIV, São Paulo, 04 a 10 mai. 1997. Disponível em: de http://giv.org.br/Ativismo-GIV/N\%C3\%A3o\%C3\%A0-palavra-Aid\%C3\%A9tico/. Acesso em: 15 de agosto de 2020

HERZLICH, C. \& PIERRET, J. "Uma Doença no Espaço Público. A AIDS em Seis Jornais Franceses". Physis: Rev. Saúde Coletiva, Rio de Janeiro, v. 15, p. 71-101, 2005 .

KAHHALE, E. P. et. al. HIV/Aids enfrentando o sofrimento psíquico. São Paulo: Cortez, 2010.

LAURENTINO, A. C. N. Políticas públicas de saúde para população LGBT: da criação do SUS à implementação da Política Nacional de Saúde Integral de LGBT. Dissertação de Mestrado em Educação Profissional em Saúde, Fundação Oswaldo Cruz, 2015.

LOURO, G. L. Gênero, Sexualidade e Educação: uma perspectiva pósestruturalista. 5 ed. Petrópolis: Vozes; 2003.

MELLO, L et al.. "Políticas de saúde para lésbicas, gays, bissexuais, travestis e transexuais no Brasil: em busca de universalidade, integralidade e equidade". Sexualidad, Salud y Sociedad, Rio de Janeiro, v. 1, n. 9, p. 7-28, 2011

MELLO, L; BRITO, W. \& MAROJA, D. "Políticas públicas para a população LGBT no Brasil: notas sobre alcances e possibilidades". Cad. Pagu, n.39, p.403-429, 2012.

OMS. Classificação de transtornos mentais e de comportamento da CID - 10: Descrições Clínicas e Diretrizes diagnósticas. Porto Alegre, RS: Artes Médicas, 1993. 
OMS/OPAS. Organização Mundial de Saúde/ Organização Pan-Americana da Saúde.

Estigma e discriminação são as principais barreiras à saúde para a população LGBT. 2016.2 Disponível em: $<$ https://www.paho.org/bra/index.php?option=com_content\&view=article\&id=5318:esti gma-e-discriminacao-sao-as-principais-barreiras-a-saude-para-a-populacaolgbt\&Itemid=820>. Acesso em: 28 de setembro de 2020 .

ONU. Declaração Universal dos Direitos Humanos. 1948. Disponível em $<$ https://www.ohchr.org/EN/UDHR/Documents/UDHR_Translations/por.pdf >. Acesso em: 06 de Setembro de 2020

OPAS. Organização Pan-Americana da Saúde. Indicadores de saúde. Elementos conceituais e práticos. Washington, D.C.: OPAS; 2018.

PACHECO, B. G. C. 2017. Psicologias e transexualidades: o estado da arte da produção teórica brasileira. Dissertação de Mestrado em Psicologia, Universidade Federal de Uberlândia.

PAIVA, C. H. A \& TEIXEIRA, L. A. "Reforma sanitária e a criação do Sistema Único de Saúde: notas sobre contextos e autores". Hist. cienc. saúde-Manguinhos, Rio de Janeiro, v. 21, n. 1, p. 15-36, 2014.

PARKER, R. \& AGGLETON, P. "Estigma, Discriminação e Aids". Coleção ABIA, Cidadania e Direitos, n. 1. Rio de Janeiro: ABIA, 2001.

PAULA, C. E. A.; SILVA, A. P. \& BITTAR, C. M. L.. "Vulnerabilidade legislativa de grupos minoritários". Ciênc. saúde coletiva, Rio de Janeiro , v. 22, n. 12, p. 3841-3848, 2017.

POCAHY, F. “(Micro)políticas queer: dissidências em pesquisa”. Textura, v. 18, n. 38, p. 8-25, 2016.

RICH, A. "Heterossexualidade compulsória e existência lésbica". Revista Bagoas: estudos gays, gêneros e sexualidades, Natal, v. 4, n. 5, p. 17-44, 2010.

RUSSO, J. \& VENÂNCIO, A. T. A. "Classificando as pessoas e suas perturbações: a "revolução terminológica" do DSM III". Rev. latinoam. psicopatol. Fundam, São Paulo, v. 9, n. 3, p. 460-483, 2006.

SALES, A.; LOPES, H. P. \& PERES, W. S.. "Despatologizando as travestilidades e transexualidades: saúde mental e direitos”. Revista Periódicus, v. 1, p. 56 -72, 2016.

TRANSGENDER EUROPE (TGEU). Trans Murder Monitoring / Observatório de Pessoas Trans Assassinadas (TEGEU, 2017). Instituto Patrícia Galvão, dados e fontes, São $2017 . \quad$ Paulo, Disponível em: https://dossies.agenciapatriciagalvao.org.br/dados-e-fontes/pesquisa/pessoas-transassassinadas/. Acesso em 08 jan. 2020.

\section{HEALTH OF THE LGBT POPULATION BEYOND HIV/AIDS AND TRANSEXUALIZING PROCESS IN SUS}


Abstract: This article is an excerpt from two empirical research carried out in the context of LGBT health, specifically in the Transexualizing Process and in HIV/AIDS assistance. Thus, the article intends to raise reflections about the set of rationalities that permeate the LGBT health configuration processes, speeches and policies involved through the report of 11 participants. This is a qualitative research that gathered reports from 6 trans women, 3 trans men and 2 gay cis men. Data were collected through semistructured interviews and analyzed using Content Analysis. The results shows important critical points in the field of health, especially the health of trans people, with the pilgrimage through health services demarcated by constant institutional discrimination allowing the understanding of how the health system is organized in relation to the care of these people, listing issues for the work of health professionals and government agents in this field.

Keywords: Health of the LGBT population. HIV/AIDS. Transexualizing Process.

\section{SALUD DE LA POBLACIÓN LGBT MÁS ALLÁ DEL VIH/SIDA Y DEL PROCESO DE TRANSEXUALIZACIÓN EN EL SUS}

Resumen: Este artículo es un extracto de dos investigaciones empíricas realizadas en el contexto de la salud LGBT, específicamente en el Proceso Transexualizador y en la atención al VIH/SIDA. Así, el artículo intenta plantear reflexiones sobre el conjunto de racionalidades que permean los procesos de configuración de salud LGBT, discursos y políticas involucradas a través del informe de 11 participantes. Esta es una investigación cualitativa que recopiló informes de 6 mujeres trans, 3 hombres trans y 2 hombres cis gay. Los datos se recopilaron mediante entrevistas semiestructuradas y se analizaron mediante Análisis de contenido. Los resultados muestran puntos críticos importantes en el campo de la salud, especialmente la salud de las personas trans, con el peregrinaje por los servicios de salud demarcado por una discriminación institucional constante que permite comprender cómo se organiza el sistema de salud en relación a la atención de estas personas, enumerando temas para el labor de los profesionales de la salud y agentes gubernamentales en este campo.

Palabras-Clave: Salud de la población LGBT. VIH/SIDA. Proceso de transexualización.

Recebido: 06/10/2020

Aceito: 14/12/2020 